Article

\title{
Toxicity and Hazards of Biodegradable and Non- Biodegradable Sunscreens to Aquatic Life of Quintana Roo, Mexico
}

\author{
Miguel Hernández-Pedraza ${ }^{1}$, José Adán Caballero-Vázquez ${ }^{2}$, Jorge Carlos Peniche-Pérez ${ }^{2}$, \\ Ignacio Alejandro Pérez-Legaspi ${ }^{3}{ }^{\circledR}$, Diego Armando Casas-Beltran ${ }^{2}$ and \\ Jesús Alvarado-Flores $2, *$ (1) \\ 1 Colegio Boston, Cancún, Quintana Roo C.P. 77535, Mexico; telluss_1504@hotmail.com \\ 2 Centro de Investigación Científica de Yucatán, Unidad de Ciencias del Agua, Cancún, \\ Quintana Roo C.P. 77500, Mexico; adan.caballero@cicy.mx (J.A.C.-V.); jorge.peniche@cicy.mx (J.C.P.-P.); \\ diego.casas@cicy.mx (D.A.C.-B.) \\ 3 División de Estudios de Posgrado e Investigación, Instituto Tecnológico de Boca del Rio, Tecnológico \\ Nacional de Mexico Boca del Rio Mexico, Veracruz C.P. 94290, Mexico; doclegaspi@gmail.com \\ * Correspondence: jesus.alvarado@cicy.mx; Tel.: +52-(998)-211-3008 (ext. 122)
}

Received: 29 February 2020; Accepted: 9 April 2020; Published: 17 April 2020

\begin{abstract}
Sunscreens have spread widely into aquatic systems over the last 18 years in Quintana Roo, Mexico. This contamination is caused by intensive use as a result of leisure activities, as sunbathers apply the substances intensively (up to $83.75 \%$ of tourists and locals). Moreover, $25 \%$ of the compounds are mainly released into the water through topical products washing off. On average, 300,000 tourists arrive every week in Quintana Roo, increasing the contamination. In addition, there are no recent studies on sunscreen toxicity and the hazards this represents for the native zooplankton of Quintana Roo. In order to assess their adverse effects, acute toxicity was assessed for nine sunscreens (five non-biodegradable and four biodegradable) in four zooplankton species (Brachionus cf ibericus, Cypridopsis vidua, Diaphanocypris meridana, and Macrothrix triserialis). In total, $21 \mathrm{LC}_{50}$ values were obtained, which are the baseline values for estimating risk and for determining the expected maximum permissible concentration. Our data on toxicity to freshwater species compared to marine species indicate that freshwater species are more sensitive than marine species. In conclusion, biodegradable sunscreen posed a moderate risk, and non-biodegradable posed a high risk. Our outcomes suggested that the maximum permissible concentrations for the contamination of sunscreens were $8.00 \mathrm{E}-05 \mathrm{~g} / \mathrm{L}$ for non-biodegradable and 1.60E-04 $\mathrm{g} / \mathrm{L}$ for biodegradable sunscreens.
\end{abstract}

Keywords: touristic impact; bioindicators; organic contamination; groundwater; Caribbean Sea

\section{Introduction}

The contamination of water caused by the intensive use of sunscreens is an environmental hazard. The tourism activity in coastal areas directly represents a major source of the contamination of marine and freshwater environments, because sunscreens contain organic and inorganic compounds that have adverse effects on the aquatic life [1]. These ingredients mostly reach the aquatic systems through the washing off of topical products used by tourists and the local population, which eventually contaminate the marine environments, freshwater systems (dolines and karstic lakes) and wildlife [2,3]. The contamination of ecosystems by sunscreens is directly related to anthropogenic activities, mainly in coastal tourist destinations. The discharge of sunscreens in tourist destinations is high, and in coastal tourist destinations with aquatic activities taking place in direct sunlight, sunscreen use increases and the problem is magnified [4]. Direct discharge is significant in quantitative terms, most probably due 
to the contamination of water by sunscreens. For example, in seawater, the minimum concentration detected is $3.03 \mathrm{E}-13 \mathrm{~g} / \mathrm{L}$, and the maximum is $1.00 \mathrm{E}-09$; in wastewater treatment plants (WWTP), the minimum is $5.49 \mathrm{E}-13$, and the maximum is $1.00 \mathrm{E}-07$; and, in general, for surface water, the minimum is $2.28 \mathrm{E}-13$, and the maximum is $1.00 \mathrm{E}-07$ [4,5]. Approximately $25 \%$ of the sunscreen applied on the skin washes off in direct contact with water [6]. In the particular case of coastal tourist destinations, Casas-Beltran et al. [7] estimated that more than 4000 tons of sunscreens have been added in the last 20 years by tourists and locals into the aquatic ecosystems of the Mexican Caribbean. Within the commercial range of sunscreens used by tourists and locals, there are conventional options (made with substances derived from oil and considered non-biodegradable), while other options are considered "friendly" to the environment, such as biodegradable sunscreen, classified by manufacturers as containing natural ingredients or products that they consider to be less harmful to the environment and aquatic life (Federal Office of the Consumer (PROFECO in Spanish)).

The number of tourists that visit the Mexican Caribbean is immense and, as a consequence, the discharge of sunscreen is increasing. This presents an adverse scenario for the ecosystem, aquatic life and human health. It is estimated that there are 1.2 million tourists on average per month in Quintana Roo, which indicates that sunscreen discharge is continuous and the ingredients in sunscreens could intensify their presence and concentration in the water and biota. In the Mexican Caribbean, water pollution is a serious problem for wildlife and the tourism economy. This is especially true for Quintana Roo, Mexico, in which tourism is an important sector of economic development; in fact, this zone receives $87 \%$ of the total tourist flow that arrives in the state [8]. The use of sunscreens by the millions of tourists who arrive every year increases the contamination of sunscreens in aquatic systems, mainly because it is considered that $89.9 \%$ of the tourists carry out aquatic activities [7]. According to Rodríguez-Fuentes et al. [9], 83.75\% of sunbathers use sunscreen in Quintana Roo. The ingredients of sunscreens could contain pollutants. The concerns intensify for society, public health and the tourism sector, because the wastewater treatment coverage in the state is low; only $68 \%$ of wastewater is treated. This results in the immense contamination of toxic compounds in aquatic systems, which are potential stressing agents for the aquatic biota of the state of Quintana Roo.

It is estimated that more than a thousand tons of sunscreen are discharged each year in aquatic systems, with more than 50 different ingredients being discharged. The presence of dozens of chemical compounds in the water increases toxicological interaction and the adverse effects are complex. It is essential to mention that all sunscreens contain several highly toxic ingredients; unfortunately, their adverse effects are devastating, inducing moderate to high mortality according to scientific reports. The behavior of the components of various sunscreens depends on their molecular characteristics, and the presence of certain functional groups are factors that determine their toxicity. Their adverse effects on the biota can cause endocrine disruption, bioaccumulation or biomagnification [2,3,10-12]. The majority of the compounds are not soluble in water, and degrade by photolysis. Their half-life is less than 20 days. The ingredients of sunscreens that are discharged in the aquatic systems are diluted; therefore, the biological effects on aquatic life depend on the magnitude of sunscreens introduced into the ecosystem. Consequently, the places with a greater prevalence of aquatic activities will be the most frequently contaminated.

In addition, little work has been done in ecotoxicology for these sites; in fact, there are no current data on the toxicity of sunscreens on native species, nor any risk assessment for Quintana Roo, Mexico. As a starting point, in the present study, our hypothesis is that biodegradable sunscreens are less toxic than non-biodegradable ones to native zooplankton. Additionally, toxicity data provide a baseline for carrying out contamination risk assessments and performing toxicological tests to determine the toxicity caused by sunscreens in aquatic ecosystems. With our current knowledge, we suggest reference values for future aquatic toxicology research. The goal was to calculate the reference values of sunscreens (in $\mathrm{g} / \mathrm{L}$ ), as a guide for decision-makers in the development of ecotouristic parks and for environmental protection agencies. The worst risk scenario in Quintana Roo is that sunscreen ingredients probably transfer from one aquatic system to another. Assessing this adverse scenario 
should take priority, due to the connectivity and the groundwater flows of the karstic systems of Quintana Roo.

\section{Materials and Methods}

\subsection{Zooplankton Sampling and Identification}

Zooplankton was collected in two aquatic systems in Quintana Roo. We completed limnetic and littoral drag sampling using a Wisconsin zooplankton net of $54 \mu \mathrm{m}$ mesh aperture, filtering approximately $500 \mathrm{~mL}$ of water per drag. Half of the sample $(250 \mathrm{~mL})$ was preserved with $4 \%$ formalin for taxonomical identification and the other $250 \mathrm{~mL}$ was kept at room temperature to perform the isolation of organisms in the laboratory and then culture them (Ecotoxicology Laboratory of the Water Sciences Unit, Yucatan Centre for Scientific Research CICY). To identify the zooplankton species, we used the dichotomy and pictorial keys of Mills et al. [13] Elías et al. [14] for cladoceran, and Nagler et al. [15] for ostracods. Samples were identified with an inverted Nikon Eclipse microscope (Tokyo, Japan), model TS 100, and with a stereoscopic Nikon SMZ745 microscope, model C-LEDS.

\subsection{Isolation and Creation of Monoclonal Cultures of the Zooplankton Species}

For the creation of monoclonal cultures of zooplankton, we followed the standardized protocols of Lopez-Gutiérrez et al. [16], Pérez-Legaspi et al. [17] and Garza-León et al. [18]. Two monoclonal cultures of rotifers were established: Sian Ka'an (19.088533N, $-87.550750 W)$ and Cancun $(21.199675 N$, $-86.818698 \mathrm{~W})$, with two different monoclonal cultures for ostracods $(21.202753 \mathrm{~N},-86.840897 \mathrm{~W})$ and one for cladocerans $(21.182637 \mathrm{~N},-89.813456)$. Rotifers and the cladocerans Macrothrix tricerialis were fed the microalgae Nannochloropsis oculata. The ostracods Cypridopsis vidua and Diaphanocypris meridana were fed common commercial lettuce and the microalgae N. oculata. The organisms were placed in Petri dishes with EPA (US Environmental Protection Agency) medium [19] containing $96 \mathrm{mg} / \mathrm{L}$ of $\mathrm{NaHCO}_{3}, 60 \mathrm{mg} / \mathrm{L}$ of $\mathrm{CaSO}_{4} \cdot 2 \mathrm{H}_{2} \mathrm{O}, 60 \mathrm{mg} / \mathrm{L}$ of $\mathrm{SO}_{4} \cdot 7 \mathrm{H}_{2} \mathrm{O}$, and $4 \mathrm{mg} / \mathrm{L}$ of $\mathrm{KCl}$, pH of 7.5, with a hardness of $80-100$ and an alkalinity of $57-64$, expressed as $\mathrm{mg} \mathrm{CaCO}_{3} / \mathrm{L}$ ). The green algae N. oculata Droop, 1955 (LB164 strain from the University of Texas collection) was cultivated in Bold's media [20]. All organisms were cultivated in a bioclimatic chamber with a photoperiod of 16:8 $\mathrm{h}$ (light/dark), at a temperature of $25 \pm 2{ }^{\circ} \mathrm{C}$. The processes of acclimatization took at least 2 months.

\subsection{Sunscreen Selection and Preparation of the Sunscreen Stock}

Sunscreens were selected from the data reported by the Federal Consumer Office, Mexico (PROFECO), as reported by Rodríguez-Fuentes et al. [9], and according to a prospective study carried out at the public entrances of two tourist beaches in the city of Cancun (Playa Delfines and Playa Gaviota Azul), and one cenote with touristic activity (Cenote Verde Lucero, Puerto Morelos), based on the methodology and sampling sites from Casas-Beltrán et al. [21]. The survey consisted of structured questions and was codified for further statistical analysis (see the Supplementary Materials). Prospective surveys were carried out from January to March 2018. The target group included tourists older than 18 years, who had spent at least one night in the location where they were sampled. Sampling was systematically taken at visitor exit points, reaching a sample size of 208 persons.

For the toxicity experiments, five commercial brands of non-biodegradable sunscreen and four biodegradable sunscreens were chosen; these were given codes-the information is shown in Table 1. The sunscreen solutions were prepared as follows: $1 \mathrm{~g}$ of sunscreen was placed in a $100 \mathrm{~mL}$ Erlenmeyer flask, and then we added $100 \mathrm{~mL}$ of the culture media (either freshwater or saltwater).

Depending on the species, the samples were cultivated in freshwater or saltwater. The flasks were placed in an orbital Shaker CVP-100B incubator, for $2 \mathrm{~h}$ at $200 \mathrm{rpm}$ and $25^{\circ} \mathrm{C}$. We used ten nominal concentrations: 1.00E-02, 2.50E-02, 5.00E-02, 1.00E-01, 2.50E-01, 1.0E+00, 2.5E+00, 5.0E+00 and $1.00 \mathrm{E}+01 \mathrm{~g} / \mathrm{L}$. Before the final exposure concentrations, exploratory tests were carried out to obtain the final exposure range. 


\subsection{Acute Toxicity Test in Zooplankton}

The experimental methods were designed following the Environmental Protection Agency manual, "Methods for Measuring the Acute Toxicity of Effluents and Receiving Waters to Freshwater and Marine Organisms" [19], Pérez-Legaspi and Rico-Martínez [22], Santos-Medrano et al. [23], and López-Gutiérrez et al. [16], and adapted to the organism used in each test. For rotifers, sterile 24-well Costar ${ }^{\circledR}$ polystyrene plates were used. Ten newborns per species were placed in $1 \mathrm{~mL}$ of culture media. Each well had a repetition and an exposure replica. Each repetition and replica had a control without sunscreen added (reference blank). Mortality was recorded at $24 \mathrm{~h}$ in order to obtain the $\mathrm{LC}_{50}$ values (the concentrations of the sunscreen in water in $\mathrm{g} / \mathrm{L}$ that killed $50 \%$ of the test animals during the observation period). For ostracods and cladocerans, sterile 24-well Costar ${ }^{\circledR}$ polystyrene plates were used. Ten newborn ostracods and five newborn cladocerans were placed in $1 \mathrm{~mL}$ of freshwater media with their respective sunscreen concentrations; $10 \%$ mortality was accepted in the control groups. In total (without taking into account the prospective experiments of acute toxicity), we used 12,960 rotifers (3240 organisms for each strain; Sian Ka'an and Cancun), 6480 ostracods (3240 for each species) and 720 cladocerans. The Maximum Allowable Toxicant Concentration (MATC) was calculated with the geometric mean of $\mathrm{LC}_{10}$. In addition, the $\mathrm{LC}_{50}$ and $\mathrm{LC}_{10}$ values were calculated by means of a linear regression analysis and Probit model, using Statistica ${ }^{\circledR}$ Version 6 (StatSoft Inc. Tulsa, OK, USA).

\subsection{Risk Assessment and Statistical Analyses}

Risk assessments were carried out for the five non-biodegradable and four biodegradable sunscreens on the five aquatic species previously mentioned. From the $\mathrm{LC}_{10}$ values, we obtained the MATC, and then estimated the maximum permissible concentration for the predicted no effect concentration (PNEC). PNEC were are used to estimate environmental risk assessments, according to Karlsson [24], Zhao and Chen [25], Cruzerio et al. [26], and Wijngaarden et al. [27], by commonly using one species from every trophic level - microalgae, cladocerans and fish. However, several authors used one or two species, notably by applying an appropriate assessment factor $(\mathrm{AF}=1000)$ to compensate for the intra- and inter-laboratory variation, biological variance, and extrapolation from the lab to the field [28].

A risk assessment $(\mathrm{RQ})$ was carried out using the following formula:

$$
\begin{gathered}
\mathrm{RQ}=\frac{\mathrm{MEC}}{\mathrm{PNEC}} \\
\mathrm{PNEC}=\frac{\mathrm{MATC}}{\mathrm{AF}}
\end{gathered}
$$

where MEC is the environmental concentration of the pollutant, PNEC is the predictive concentration at which no adverse effect is observed, MATC is the maximum allowable toxicant concentration and $\mathrm{AF}$ is the assessment factor. The interpretation of $\mathrm{RQ}$ values was as follows: $<0.1=$ negligible risk; $0.1-1.0=$ low risk; $1.0-10=$ moderate risk; and $>10=$ high risk. As a reference for interpretation, a low PNEC value meant the toxicity of the substance was high, while a high value of PNEC meant that the toxicity of the substance was low. In risk assessments, PNEC must always be high with regard to the environmental concentration of the substance in question; on the contrary, environmental risk increases according to the interpretation of Beyer et al. [28]. As a second step in the assessment of environmental risks, the environmental concentration of the pollutant (MEC) was obtained from the information taken from the scientific literature on the environmental concentrations of the components of the sunscreens used in these toxicity tests.

\section{Results}

\subsection{Statistics on Sunscreens, Quintana Roo, Mexico}

The results obtained from the 208 surveys carried out in Quintana Roo identified 54 brands of sunscreens, of which $12.96 \%$ are classified as biodegradable and $87.03 \%$ as non-biodegradable. 
The brands most used by the tourists in the three sites were Coopertone Babe ${ }^{\circledR}$, Hawaiian Tropic ${ }^{\circledR}$, Nivea Sun ${ }^{\circledR}$, and Banana Boat ${ }^{\circledR}$. Sunscreens used in Quintana Roo that were cataloged as biodegradable were the following: Kiinsun, Maya Solar, Protectyl Vegetal, and Hawaiian Tropic ${ }^{\circledR}$.

The potential introduction of sunscreen via skin washes in tourists was high, since $67 \%$ of the tourists surveyed admitted to having used sunscreen and, of these, the average application was 2.16 times per hour. The sites that could have the greatest contribution of sunscreen per visit by tourists were beaches $(47 \%)$, cenotes $(22 \%)$, mangroves $(12 \%)$ and thematic parks $(19 \%)$, with the averages of the visits to each site being 2.3, 1.4, 1.1 and 1.2 respectively. On the other hand, despite this, there was generally some awareness among respondents about the impact of sunscreens in aquatic environments. A total of $67 \%$ of respondents recognized that sunscreens in some way or another produce an adverse effect on the biota of aquatic environments, although it should be noted that only $35 \%$ recognized that non-biodegradable sunscreens could also produce negative effects on the biota. Finally, despite this, $92 \%$ of the respondents would be willing to use other alternative methods of sun protection (Sun-Protective Clothing). For more details, see the conceptual contamination model of sunscreens in Figure 1.
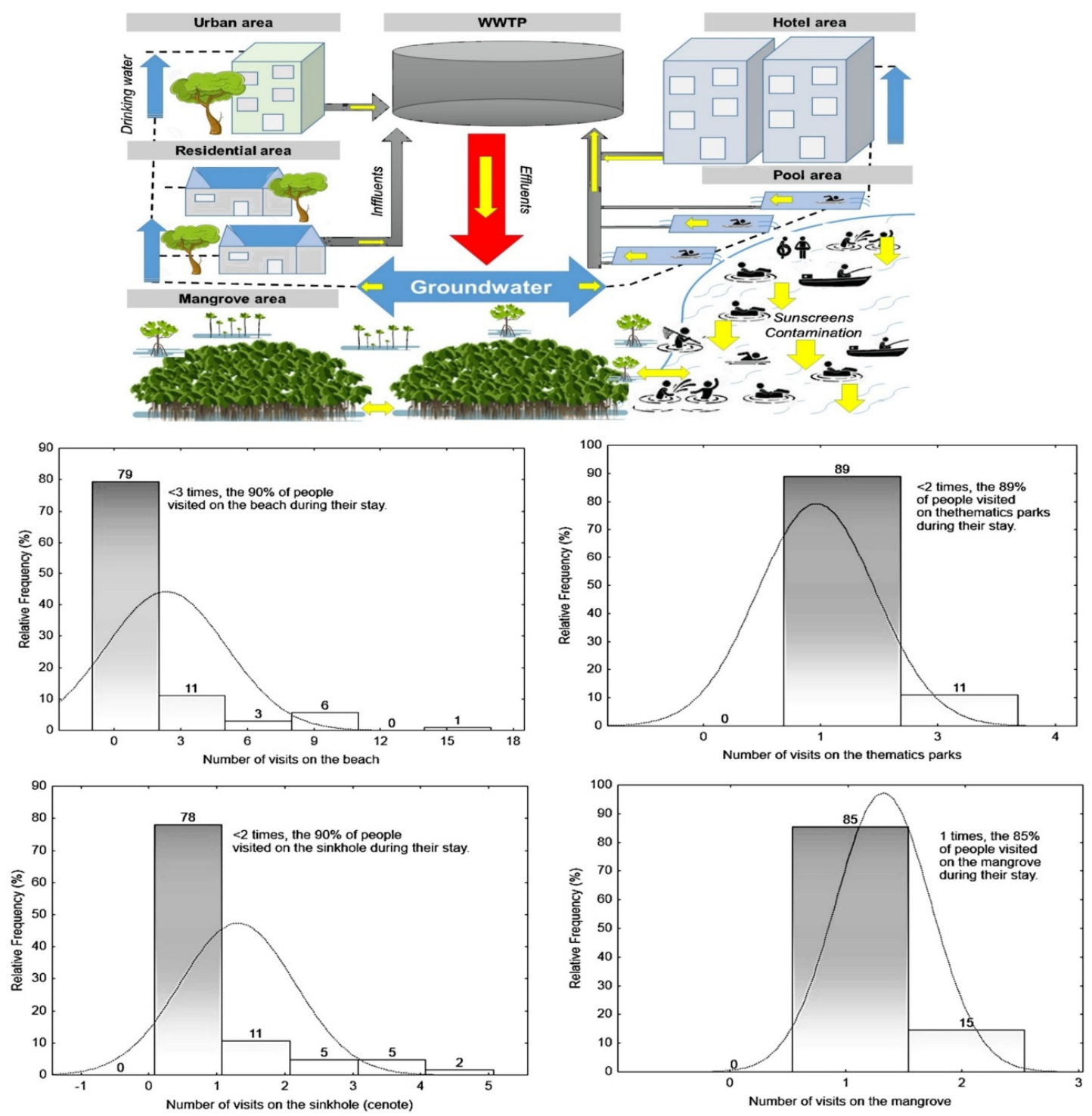

Figure 1. Fitting of continuous distributions (relative frequency \%) from interviews of 208 people in three sites (two beaches and one sinkhole) in Quintana Roo. The yellow arrow in the conceptual contamination model indicates the direct discharge of sunscreen to water and its distribution from the aquatic systems to the aquifer, then from drinking water to the wastewater treatment plant (WWTP). 


\subsection{Bioindicator Species}

Four species were isolated from two aquatic ecosystems in the state of Quintana Roo: Brachionus cf. ibericus (marine rotifer), Macrothrix trisearilis (freshwater cladoceran), Diaphanocypris meridana (freshwater ostracod), and Cyprodopsis vidua (freshwater ostracod). These species acclimated to laboratory conditions acceptably. All species were isolated from the coastal area of Quintana Roo, the cladocerans and the rotifers are eurihaline species, while the ostracods are freshwater. The four species (five monoclonal cultures) represent a group comprised of specific species that are useful for aquatic toxicology studies in the aquatic ecosystems of Quintana Roo.

\subsection{Toxicity of Sunscreens in Zooplankton Species}

A total of 21 values for $\mathrm{LC}_{50}$ were obtained. All the $\mathrm{LC}_{50}$ values are shown in Table 1 . The most significant results from the toxicity tests of biodegradable sunscreens were found for Hawaiian Tropic ${ }^{\mathrm{TM}}$ Biodegradable (TBO, B4), which was the most toxic for zooplankton, with an $\mathrm{LC}_{50}$ value of $1.80 \mathrm{E}-01 \mathrm{~g} / \mathrm{L}$. Sunscreen Kiin Sun (B-1) was the least toxic for zooplankton and its $\mathrm{LC}_{50}$ value was $6.77 \mathrm{E}+00 \mathrm{~g} / \mathrm{L}$. Regarding non-biodegradable sunscreens, Banana Boat (NB1) was the most toxic, with an $\mathrm{LC}_{50}$ value of 3.00E-02 g/L. Nivea Sun (NB-5) was the least toxic and it is $\mathrm{LC}_{50}$ value was $2.46 \mathrm{E}+00 \mathrm{~g} / \mathrm{L}$.

Table 1. Acute toxicity of biodegradable (B) and non-biodegradable (NB) sunscreens to native zooplankton of Quintana Roo, Mexico. Clone culture in laboratory conditions (C). BO = Biodegradable; $\mathrm{ST}=$ Sheer Touch; $\mathrm{O}=$ Ozone.

\begin{tabular}{|c|c|c|c|c|c|}
\hline Species & Sunscreens & Keys & $\mathbf{r}^{2}$ & $\mathrm{LC}_{50} \mathrm{~g} / \mathrm{L}$ & $\mathrm{LC}_{10} \mathrm{~g} / \mathrm{L}$ \\
\hline Brachionus cf ibericus SianKan C7 & Kinsun & B1 & 0.888 & $1.68 \mathrm{E}+00$ & 7.00E-01 \\
\hline Cypridopsis vidua & Kinsun & B1 & 0.921 & $1.53 \mathrm{E}+00$ & 4.51E-01 \\
\hline Diaphanocypris meridana & Kinsun & B1 & 0.999 & $6.77 \mathrm{E}+00$ & 7.00E-01 \\
\hline D. meridana & Maya Solar & B2 & 0.978 & 3.90E-01 & $1.00 \mathrm{E}-02$ \\
\hline Cypridopsis vidua & Protectyl Vegetal & B3 & 0.891 & 3.40E-01 & 8.00E-02 \\
\hline Brachionus cf ibericus Cancun C16 & Hawaiian Tropic ${ }^{\mathrm{TM}} \mathrm{BO}$ & $\mathrm{B} 4$ & 0.932 & $5.00 \mathrm{E}-01$ & $1.60 \mathrm{E}-01$ \\
\hline B. cf ibericus Cancun C20 & Hawaiian Tropic ${ }^{\mathrm{TM}} \mathrm{BO}$ & B4 & 0.736 & $6.50 \mathrm{E}-01$ & $1.90 \mathrm{E}-01$ \\
\hline B. cf ibericus SianKan C6 & Hawaiian Tropic ${ }^{\mathrm{TM}} \mathrm{BO}$ & B4 & 0.898 & 6.30E-01 & 2.20E-01 \\
\hline B. cf ibericus SianKan C7 & Hawaiian Tropic ${ }^{\mathrm{TM}} \mathrm{BO}$ & B4 & 0.907 & $5.40 \mathrm{E}-01$ & $1.70 \mathrm{E}-01$ \\
\hline Cypridopsis vidua & Hawaiian Tropic ${ }^{\mathrm{TM}} \mathrm{BO}$ & B4 & 0.903 & 3.30E-01 & $1.80 \mathrm{E}-01$ \\
\hline Diaphanocypris meridana & Hawaiian Tropic ${ }^{\mathrm{TM}} \mathrm{BO}$ & B4 & 0.872 & $1.80 \mathrm{E}-01$ & $4.00 \mathrm{E}-02$ \\
\hline Cypridopsis vidua & Banana Boat & NB1 & 0.893 & 2.10E-01 & $1.00 \mathrm{E}-01$ \\
\hline Diaphanocypris meridana & Banana Boat & NB1 & 0.824 & $1.00 \mathrm{E}-01$ & $1.00 \mathrm{E}-02$ \\
\hline Macrothrix triserialis & Banana Boat & NB1 & 0.917 & $1.00 \mathrm{E}+00$ & 4.60E-01 \\
\hline Cypridopsis vidua & Coopertone Babe & NB2 & 0.839 & 2.30E-01 & $1.10 \mathrm{E}-01$ \\
\hline Diaphanocypris meridana & Coopertone Babe & NB2 & 0.947 & 2.30E-01 & $7.00 \mathrm{E}-02$ \\
\hline D. meridana & Hawaiian Tropic ${ }^{\mathrm{TM}}$ ST & NB3 & 0.869 & $1.80 \mathrm{E}-01$ & $5.00 \mathrm{E}-02$ \\
\hline Macrothrix triserialis & Hawaiian Tropic ${ }^{\mathrm{TM}}$ ST & NB3 & 0.804 & 2.70E-01 & $7.00 \mathrm{E}-02$ \\
\hline Cypridopsis vidua & Hawaiian Tropic ${ }^{\mathrm{TM}} \mathrm{O}$ & NB4 & 0.937 & 2.30E-01 & 4.00E-02 \\
\hline Diaphanocypris meridana & Hawaiian Tropic ${ }^{\mathrm{TM}} \mathrm{O}$ & NB4 & 0.946 & 4.80E-01 & $2.00 \mathrm{E}-02$ \\
\hline D. meridana & Nivea Sun & NB5 & 0.934 & $2.46 \mathrm{E}+00$ & $6.60 \mathrm{E}-01$ \\
\hline
\end{tabular}

The Maximum Allowable Toxicant Concentration (MATC), obtained using our acute $\mathrm{LC}_{10}$ values, is shown in Table 1. In general, the biodegradable sunscreens' MATC was $1.57 \mathrm{E}-01 \mathrm{~g} / \mathrm{L}$, while for non-biodegradable sunscreens, it was 7.60E-02 g/L. The MATC of Nivea Sun (NB5) was the highest, and its value was $6.60 \mathrm{E}-01 \mathrm{~g} / \mathrm{L}$, while Maya Solar was the lowest and its value was $1.00 \mathrm{E}-02 \mathrm{~g} / \mathrm{L}$. The calculated PNECs in $\mathrm{g} / \mathrm{L}$ are shown in Table 2. PNEC can be used as the suggested maximum permissible concentration of contamination by sunscreens; according to our toxicity results, the suggested maximum permissible concentrations of contamination by sunscreens are, for non-biodegradable sunscreens, 8.00E-05 $\mathrm{g} / \mathrm{L}$ and, for biodegradable sunscreens, $1.60 \mathrm{E}-04 \mathrm{~g} / \mathrm{L}$. 


\subsection{Risk Assessment}

Based on the previous results, environmental risk assessments for the biodegradable and non-biodegradable sunscreens were carried out. For these analyses, $\mathrm{LC}_{10}$ values were used, as well as the environmental concentration of components present in the sunscreens (MEC $=1.00 \mathrm{E}-03 \mathrm{~g} / \mathrm{L})$, according to Karlsson [24], Zhao and Chen [25], Cruzerio et al. [26], and Wijngaarden et al. [27]. Based on our results, each sunscreen had a different risk characterization, based on the toxicity found in toxicological tests. The results of the risk assessment are shown in Table 2. The sunscreens with high risks to aquatic life were Maya Solar, Banana Boat, Coopertone@Babe, Hawaiian Tropic ${ }^{\mathrm{TM}}$ Sheer Touch and Hawaiian Tropic ${ }^{\mathrm{TM}}$ Ozone. Those with moderate risks to aquatic life were Kinsun, Protectyl Vegetal and Nivea Sun. In general, biodegradable (B) sunscreen posed moderate risks to aquatic life, while non-biodegradable (NB) posed high risks to aquatic life.

Table 2. Risk assessment and toxicity of sunscreens, according to $\mathrm{LC}_{10}$ values estimated using zooplankton from Quintana Roo, Mexico. Maximum Allowable Toxicant Concentration (MATC). $\mathrm{BO}=$ Biodegradable; $\mathrm{ST}=$ Sheer Touch; $\mathrm{O}=$ Ozone.

\begin{tabular}{|c|c|c|c|c|c|}
\hline Sunscreens & Keys & $\begin{array}{c}\text { MATC of } \\
\mathrm{LC}_{10} \text { in } \mathrm{g} / \mathrm{L}\end{array}$ & PNEC in $\mathrm{g} / \mathrm{L}$ & $\begin{array}{c}\text { RQ = MEC } \\
(0.001 \mathrm{~g} / \mathrm{L}) / \mathrm{PNEC}\end{array}$ & Interpretation \\
\hline Kinsun & B1 & $6.05 \mathrm{E}-01$ & $6.05 \mathrm{E}-04$ & $1.65 \mathrm{E}+00$ & Moderate \\
\hline Maya Solar & B2 & $1.00 \mathrm{E}-02$ & $1.00 \mathrm{E}-05$ & $1.00 \mathrm{E}+02$ & High \\
\hline Hawaiian Tropic ${ }^{\mathrm{TM}}$ BO & B3 & 1.42E-01 & $1.42 \mathrm{E}-04$ & $7.04 \mathrm{E}+00$ & Moderate \\
\hline Protectyl Vegetal & B4 & 8.00E-02 & 8.00E-05 & $1.25 \mathrm{E}+01$ & High \\
\hline Banana Boat & NB1 & 7.72E-02 & 7.72E-05 & $1.30 \mathrm{E}+01$ & High \\
\hline Coopertone®Babe & NB2 & 8.77E-02 & 8.77E-05 & $1.14 \mathrm{E}+01$ & High \\
\hline Hawaiian Tropic $^{\mathrm{TM}}$ ST & NB3 & 5.92E-02 & 5.92E-05 & $1.69 \mathrm{E}+01$ & High \\
\hline Hawaiian Tropic ${ }^{\mathrm{TM}} \mathrm{O}$ & NB4 & 2.83E-02 & $2.83 \mathrm{E}-05$ & $3.54 \mathrm{E}+01$ & High \\
\hline Nivea Sun & NB5 & $6.60 \mathrm{E}-01$ & $6.60 \mathrm{E}-04$ & $1.52 \mathrm{E}+00$ & Moderate \\
\hline Biodegradable & B & $1.57 \mathrm{E}-01$ & $1.57 \mathrm{E}-04$ & $6.36 \mathrm{E}+00$ & Moderate \\
\hline Non-Biodegradable & NB & 7.61E-02 & 7.61E-05 & $1.31 \mathrm{E}+01$ & High \\
\hline
\end{tabular}

\section{Discussion}

The toxicity data hereby obtained is considered as a baseline for understanding the risks to aquatic life in Quintana Roo. Acute toxicity in zooplankton species was mainly obtained with original sunscreen formulations, which are actually a mixture of components, with a few recognized as active ingredients and the rest as part of the formulation. The sensitivity of the zooplankton species studied ranged between $\mathrm{LC}_{50}$ values of $1.00 \mathrm{E}-01 \mathrm{~g} / \mathrm{L}$ and $6.7 \mathrm{E}+00 \mathrm{~g} / \mathrm{L}$. It is important to stress that the evaluated toxicity refers to the mixture of components present in one single formula, and the adverse effects of a single chemical may not be captured, or it can be altered, owing to interactions between chemicals and the physiochemical properties of the substances in the solution [29,30]. Consequently, the toxicity of sunscreen was difficult to assess during the exposure tests, because the complexity of the sunscreens typically include a combination of oxybenzone, avobenzone, octisalate, octocrylene (OCT), homosalate and octinoxate, and other substances. Additionally, the water solubility of the ingredients is different. For example, according to PubChem [31], the solubility for camphor is $1.60 \mathrm{E}+00 \mathrm{~g} / \mathrm{L}$, for benzophenone it is $1.37 \mathrm{E}-01 \mathrm{~g} / \mathrm{L}$, for triazone it is $2.30 \mathrm{E}+02-3.50 \mathrm{E}+02 \mathrm{~g} / \mathrm{L}$, for drometrizole it is $7.03 \mathrm{E}-05 \mathrm{~g} / \mathrm{L}, \mathrm{OCT}$ is $6.85 \mathrm{E}-02 \mathrm{~g} / \mathrm{L}$, for titanium dioxide $\left(\mathrm{TiO}_{2}\right)$ it is $<1.00 \mathrm{E}+00 \mathrm{~g} / \mathrm{L}$ and, for zinc oxide $(\mathrm{ZnO})$, it is $7.45 \mathrm{E}-03 \mathrm{~g} / \mathrm{L}$.

In other studies, the toxicity of isolated ingredients in indicator species has been determined. For example, reports on anatase and rutile acute toxicity in cladocerans and rotifers produced $\mathrm{LC}_{50}$ values between 9.90E-04 g/L and 9.47E-02 $\mathrm{g} / \mathrm{L}-\mathrm{a}$ lower range than our results. In addition, when compared with toxicological data obtained for cladocerans on acute toxicity from active ingredients such as oxybenzone and camphor, the $\mathrm{LC}_{50}$ values ranged from 1.90E-03 to 5.00E-02 g/L [32]. Acute toxicity $\left(\mathrm{LC}_{50}\right)$ values in other aquatic species (Pimephales promelas, Danio rero, and Oncorhynchus mykiss) range from $2.80 \mathrm{E}-04 \mathrm{~g} / \mathrm{L}$ to $1.25 \mathrm{E}-01 \mathrm{~g} / \mathrm{L}$ according to Kapler et al. [33], Heinlaan et al. [34] and Fent et al. [35]. Therefore, our acute toxicity values are higher than those of isolated ingredients. 
Nonetheless, our baseline values contribute to the knowledge about risk assessments to the aquatic life of Quintana Roo, Mexico.

Contamination by sunscreens is complex and difficult to study, and the interpreted quantifications reported by several authors mention that sunscreen ingredients are variable, as a consequence of their variable use among the population and the intensity of water activities. For example, Gago-Ferrero et al. [36] studied three ingredients of sunscreens in wastewater treatment plants. According to their conclusions, 4-methyl-benzilidine-camphor (4MBC), OCT, and 2-ethyl-hexyl-4-trimethoxycinnamate (EHMC) are high toxicity ingredients. The high concentrations of these components could be explained according to Balmer et al. [32] in a study conducted in Switzerland, where they reported that, for 10,000 people per day, the wastewater influent contained $118 \mathrm{~g}$ of EHMC, $4.90 \mathrm{E}+01 \mathrm{~g}$ of $4 \mathrm{MBC}, 6.90 \mathrm{E}+01 \mathrm{~g}$ of benzophenone-3 (BP-3), and $2.80 \mathrm{E}+01 \mathrm{~g}$ of OC. Additionally, contamination by sunscreen in the environment is extraordinarily inconstant, because it depends on the intensity of anthropogenic activities and because sunscreen enters ecosystems via the washing off of topical products used by tourists and the local population.

Tons of sunscreen are discharged to aquatic ecosystems, especially in touristic areas. For example, the discharge of EHMC, OCT, $4 \mathrm{MBC}$ and nanoparticles of $\mathrm{TiO} 2$ has been estimated to be between 1 ton and more than 1000 tons per year. In this context, the study carried out by Casas-Beltran et al. [7] estimated that 4367.25 tons were discharged in the Mexican Caribbean in the last 18 years. Consequently, aquatic ecosystems are frequently contaminated by sunscreens. Likewise, it is important to consider that most of the compounds are not soluble in water, they degrade by photolysis and their half-life is less than 20 days, but they can also bioaccumulate [4]. According to a study carried out by Sanchez-Quiles and Tovar-Sánchez [4], the direct discharge of sunscreens is quantitatively the most probable method of contamination. For example, in seawater, the minimum concentration detected was $3.03 \mathrm{E}-13 \mathrm{~g} / \mathrm{L}$, and the maximum was $1.00 \mathrm{E}-09$; in wastewater treatment plants, the minimum was $5.49 \mathrm{E}-13$ and the maximum was $1.00 \mathrm{E}-07$, and, in general, for surface water, the minimum was 2.28E-13, and the maximum was 1.00E-07. In conclusion, the quantification data in water do not exceed $1.00 \mathrm{E}-03 \mathrm{~g} / \mathrm{L}$ in surface water. However, it is important to mention that the discharge of sunscreens is continuous in coastal tourist sites (such as Cancun, Acapulco, Puerto Vallarta, Mazatlán and Los Cabos). In fact, the most important coastal tourist site is Cancun Quintana Roo, which receives $\sim 50 \%$ of international tourism. It is reported that, in the Mexican Caribbean, every week, there are approximately 354,000 tourists, and a total of 17,146,971 tourists arrived in Quintana Roo in 2019 [7]. This implies that there is permanent water contamination by sunscreens throughout the year and, unfortunately, there are no quantification data in the aquatic ecosystems of Quintana Roo.

Moreover, the water activities that take place in Quintana Roo are located in areas with high permeability and rock porosity $[7,21]$. In addition to the entrance of sunscreens from recreational activities such as swimming and washing in sinkholes, mangles and coastlines (through direct contamination), they also enter the aquatic ecosystems via WWTPs via indirect contamination [32]. The allowed amount of ingredients used in the formulation of sunscreens has been specified: BP-3 is allowed up to $14 \%$, while values of $8 \%, 48 \%$ and $52 \%$ are allowed for $4 \mathrm{MBC}, \mathrm{TiO}_{2}$ and $\mathrm{ZnO}$, respectively. In other words, the most toxic ingredients are less prevalent. However, a contaminant that is not very toxic but it is used in large quantities can be toxic in the long term. The magnitude of ingredients that contaminate the water from the use of sunscreens is large, and the quantity of substances they contain increases the contamination problematic. The salts $\mathrm{TiO}_{2}$ and $\mathrm{ZnO}$ present a hazard to life, as mentioned by Sánchez-Quiles et al. [4]; the nanoparticles of $\mathrm{TiO}_{2}$ and $\mathrm{ZnO}$ that are contained in sunscreens are capable of producing $\mathrm{H}_{2} \mathrm{O}_{2}$, causing oxidative stress in marine organisms.

Sunscreens are persistent contaminants; the real magnitude of the problem of contamination of sunscreen ingredients in water is difficult to ascertain and can only be estimated [7]. Consequently, we consider this situation to be a hazard to aquatic life, because sunscreens have lethal and sublethal effects, they can bioaccumulate and biomagnify, and, consequently, they may cause mortality, morphological alterations and endocrine disruption in aquatic life [2,3,5,12]. Aquatic toxicology 
tests are used in environmental risk assessments when we have concerns about the chemicals products release into water, such as sunscreens. The objective is to provide a guide to the potential hazards. Our data on sunscreen toxicity in freshwater zooplankton species compared to marine species indicate that freshwater species are more sensitive than marine species. However, despite the differences in toxicity, it is important to use both bioindicators to estimate the environmental risk, given that tourism and aquatic activities are carried out in various aquatic ecosystems, such as coral reefs, beaches, coastal lagoons, karst lakes and dolines. In addition, by using just one indicator or generalizing with one species, we would be underestimating the adverse effects of sunscreens on our aquatic ecosystems. Another important aspect to highlight is the increase in population in coastal areas and the associated tourism, which directly or indirectly increases the discharge of sunscreen into the water. For this reason, it is essential to quantify, in salt and freshwater, the formulations or active ingredients of sunscreen in order to identify the magnitude of the contamination in quantitative terms, particularly when there is a large tourist influx.

Finally, our outcomes suggest that the maximum permissible concentration of contamination by non-biodegradable sunscreens is $8.00 \mathrm{E}-05 \mathrm{~g} / \mathrm{L}$ and, for biodegradable sunscreens, it is $1.60 \mathrm{E}-04 \mathrm{~g} / \mathrm{L}$, according to our risk assessment. These values correspond to the calculated predicted no effect concentration (PNEC) as an environmental quality standard (EQS), expressed as the maximum permissible concentration, according to Cruzerio et al. [26]. In fact, these values indicate a concentration in water that produces adverse effects, and our values should be used to avoid these risks. The maximum allowable values calculated by us are two to three orders of magnitude below the maximum concentration suggested in water by several authors [3,6,32-36]. However, risk studies reported that $4 \mathrm{MBC}$ posed a high risk to algae, while BP-3 and EHMC were more likely to pose a risk to fish. [37]. In summary, the toxicities and risk assessments reported in the present study offer a wide-ranging analysis of the sensitivity of aquatic life to acute exposure to biodegradable and non-biodegradable sunscreens for $24 \mathrm{~h}$.

\section{Conclusions}

Biodegradable sunscreen poses a moderate risk, while non-biodegradable sunscreen poses a high risk to the aquatic life of Quintana Roo, Mexico. Non-biodegradable sunscreens are the most-used sunscreens in Quintana Roo, Mexico, by tourists; therefore, the hazard is high and imminent for aquatic life according to our data. The discharge of sunscreens increases with the arrival of tourists to the coastal zone and touristic parks. The private sector, civil organization and environmental protection agencies of Mexico have attempted to increase the responsiveness among society and tourists to use non-toxic sunscreens or other sun protection methods. However, the influx increases every year; therefore, sunscreen studies must be multidisciplinary, require quantification studies of substances in water, and increase toxicity tests with native species to estimate the potential risks to the aquatic ecosystems that are the basis of the economy of Quintana Roo.

Supplementary Materials: The following are available online at http://www.mdpi.com/2071-1050/12/8/3270/s1, Figure 1. Fitting of continuous distributions (relative frequency \%) from interviews of 208 people in three sites (two beaches and one sinkhole) in Quintana Roo, Table 1. Acute toxicity of biodegradable (B) and non-biodegradable (NB) sunscreens to native zooplankton of Quintana Roo, Mexico. Clone culture in laboratory conditions (C), Table 2. Risk assessment and toxicity of sunscreens, according to $\mathrm{LC}_{10}$ values estimated using zooplankton from Quintana Roo, Mexico. Maximum Allowable Toxicant Concentration (MATC), and Survey.

Author Contributions: Conceptualization, J.A.C.-V., I.A.P.-L. \& J.A.-F.; Formal analysis, M.H.-P. \& J.A.-F.; Funding acquisition, J.A.C.-V. and J.A.-F.; Investigation, M.H.-P., J.C.P.-P. \& D.A.C.-B.; Writing-original draft, M.H.-P., J.A.C.-V., I.A.P.-L. \& J.A.-F.; Writing-review \& editing, J.A.C.-V., I.A.P.-L., D.A.C.-B. \& J.A.-F. All authors have read and agreed to the published version of the manuscript.

Funding: This work was funded by project \#2944 Cathedra's CONACYT.

Acknowledgments: Special appreciation to the staff of Cenote Verde Lucero for granting us access and for their cooperation in the interviews; to the people who personally consented to take the survey. Also to the group of Ecotoxicology of the Ecology Line, in like manner to the groups of research lines on Hydrogeology and Water Quality for their comments and suggestions to the manuscript. To Damián Rosiles and Mariana De 
Gante, participants in Talent CICY 2016, CICY A.C. The first authors thanks to CONACYT for the scholarship number 815661.

Conflicts of Interest: The authors declare no conflict of interest.

\section{References}

1. McCoshum, S.; Schlarb, M.A.; Baum, A.K. Direct and indirect effects of sunscreen exposure for reef biota. Hydrobiologia 2016, 776, 139-146. [CrossRef]

2. Giokas, D.L.; Salvador, A.; Chisvert, A. UV filters: From sunscreens to human body and the environment. TrAC Trends Anal. Chem. 2007, 26, 360-374. [CrossRef]

3. Brausch, J.M.; Rand, G.M. A review of personal care products in the aquatic environment: Environmental concentrations and toxicity. Chemosphere 2011, 82, 1518-1532. [CrossRef] [PubMed]

4. Sánchez-Quiles, D.; Tovar-Sánchez, A. Are sunscreens a new environmental risk associated with coastal tourism? Environ. Int. 2015, 83, 158-170. [CrossRef]

5. Poiger, T.; Buser, H.-R.; Balmer, E.M.; Bergqvist, P.-A.; Müller, M.D. Occurrence of UV filter compounds from sunscreens in surface waters: Regional mass balance in two Swiss lakes. Chemosphere 2004, 55, 951-963. [CrossRef] [PubMed]

6. Danovaro, R.; Bongiorni, L.; Corinaldesi, C.; Giovannelli, D.; Damiani, E.; Astolfi, P.; Greci, L.; Pusceddu, A. Sunscreens Cause Coral Bleaching by Promoting Viral Infections. Environ. Health Perspect. 2008, 116, 441-447. [CrossRef] [PubMed]

7. Casas-Beltrán, D.; Hernández-Pedraza, M.; Alvarado-Flores, J. Estimation of the Discharge of Sunscreens in Aquatic Environments of the Mexican Caribbean. Environments 2020, 7, 15. [CrossRef]

8. SECTUR. Resultados de la Actividad Turística. 2018. Available online: https://www.datatur.sectur.gob.mx/ RAT/RAT-2018-12(ES).pdf (accessed on 10 December 2019).

9. Rodríguez-Fuentes, G.; Luna-Ramírez, K.; Soto, M. Sunscreen use behavior and most frequently used active ingredients among beachgoers on Cancun, Mexico. WebmedCentral Dermatol. 2010, 1, WMC001364. [CrossRef]

10. Bozec, Y.M.; Acosta-González, G.; Núñez-Lara, E.; Arias-González, J.E. Impacts of coastal development on ecosystem structure and function of Yucatan coral reefs, Mexico. In Proceedings of the 11th International Coral Reef Symposium, Fort Lauderdale, FL, USA, 7-11 July 2008; Volume 2, pp. 691-695.

11. Sieratowicz, A.; Kaiser, D.; Behr, M.; Oetken, M.; Oehlmann, J. Acute and chronic toxicity of four frequently used UV filter substances for Desmodesmus subspicatus and Daphnia magna. J. Environ. Health Sci. Part A 2011, 46, 1311-1319. [CrossRef]

12. Clément, L.; Hurel, C.; Marmier, N. Toxicity of $\mathrm{TiO}_{2}$ nanoparticles to cladocerans, algae, rotifers and plants-Effects of size and crystalline structure. Chemosphere 2013, 90, 1083-1090. [CrossRef]

13. Mills, S.; Alcántara-Rodríguez, J.A.; Ciros-Pérez, J.; Gómez, A.; Hagiwara, A.; Galindo, K.H.; Jersabek, C.D.; Malekzadeh-Viayeh, R.; Leasi, F.; Lee, J.S.; et al. Fifteen species in one: Deciphering the Brachionus plicatilis species complex (Rotifera, Monogononta) through DNA taxonomy. Hydrobiologia 2017, 796, 39-58. [CrossRef]

14. Elías-Gutiérrez, M.; Suárez-Morales, E.; Gutiérrez Aguirre, M.A.; Silva-Briano, M.; Granados Ramírez, J.G.; Garfias Espejo, T. Cladócera y Copépoda de las Aguas Continentales de Mexico. Guía Ilustrada; Ávila Valdivieso, J.M., Ed.; Universidad Nacional Autónoma de Mexico: Ciudad de Mexico, Mexico, 2008.

15. Nagler, C.; Geist, J.; Matzke-Karasz, R. Revision of genus Tanycypris Ostrácoda, Cypricercinae) con la description de Tanycypris alfonsin. sp., and an identification key to the genus. Zootaxa 2014, 4, 401-424. [CrossRef]

16. López-Gutiérrez, L.F.; Rubio-Franchini, I.; Rico-Martínez, R.; Mesquita-Joanes, F.; Ramírez-López, E.M.; Arredondo-Figueroa, J.L.; Silva-Briano, M. Inter- and Intraspecific Variability in Invertebrate Acute Toxicity Response to Arsenic and Fluoride Exposure. J. Environ. Health Sci. 2018, 4, 1-10.

17. Pérez-Legaspi, I.A.; Garatachia-Vargas, M.; García-Villar, A.M.; Rubio-Franchini, I. Evaluación de la sensibilidad del cladócero tropical Ceriodaphnia cornuta a metales pesados. Rev. Int. Contam. Ambient. 2017, 33, 49-56. [CrossRef]

18. Garza-León, C.V.; Arzate-Cárdenas, M.A.; Rico-Martínez, R. Toxicity evaluation of cypermethrin, glyphosate, and malathion, on two indigenous zooplanktonic species. Environ. Sci. Pollut. Res. 2017, 24, 18123-18134. [CrossRef] [PubMed] 
19. EPA. Methods for Measuring the Acute Toxicity of Effluents and Receiving Waters to Freshwater and Marine Organisms; Office of Water (4303T): Washington, DC, USA, 2002.

20. Nichols, H.W. Growth media-freshwater. In Handbook of Physiological Methods; Stein, R., Ed.; Cambridge University Press: Cambridge, UK, 1973.

21. Casas-Beltrán, D.A.; Gallaher, C.; Maloof, Y.; Hernandez, E.; Moreno, K.F.; Voglesonger, K.; Leal-Bautista, R.M.; Lenczewski, M. Seaweed Invasion! Temporal Changes in Beach Conditions Lead to Increasing Cenote Usage and Contamination in the Riviera Maya. Sustainability 2020, 12, 2474. [CrossRef]

22. Pérez-Legaspi, I.A.; Rico-Martínez, R. Acute toxicity test on three species of the genus Lecane (Rotifera:Monogononta). Hydrobiologia 1998, 446, 375-381.

23. Santos-Medrano, G.; Rico-Martínez, R. Acute Sensitivity Comparison among Daphnia magna Straus, 1820 Daphnia pulex Leydig, 1860 and Simocephalus vetulus Müller, 1776, Exposed to Nine Toxicants. Turk. J. Fish. Aquat. Sci. 2018, 19, 615-623.

24. Karlsson, C. Risk Assessment of Compounds that Could Impair the Aquatic Environment; Swedish Environmental Protection Agency: Stockholm, Sweden, 2007; pp. 1-56.

25. Zhao, J.; Chen, B. Species sensitivity distribution for chlorpyrifos to aquatic organisms: Model choice and sample size. Ecotoxicol. Environ. Saf. 2016, 125, 161-169. [CrossRef]

26. Cruzeiro, C.; Amaral, S.; Rocha, E.; Rocha, M.J. Determination of 54 pesticides in waters of the Iberian Douro River estuary and risk assessment of environmentally relevant mixtures using theoretical approaches and Artemia salina and Daphnia magna bioassays. Ecotoxicol. Environ. Saf. 2017, 14, 126-134. [CrossRef]

27. Beyer, J.; Petersen, K.; Song, Y.; Russ, A.; Grung, M.; Bakke, T.; Tollefsen, K.E. Environmental risk assessment of combined effects in aquatic ecotoxicology: A discussion paper. Mar. Environ. Res. 2014, 96, 81-91. [CrossRef] [PubMed]

28. Van Wijngaarden, R.P.A.; Arts, G.H.P.; Belgers, J.D.M.; Boonstra, H.; Rossink, I.; Schroer, A.F.W.; Brock, T.C.M. The species sensitivity distribution approach compared to a microcosm study: A case study with the fungicide fluazinam. Ecotoxicol. Environ. Saf. 2010, 73, 109-122. [CrossRef] [PubMed]

29. Backhaus, T.; Faust, M. Predictive environmental risk assessment of chemical mixtures: A conceptual framework. Environ. Sci. Technol. 2012, 46, 2564-3573. [CrossRef] [PubMed]

30. Kim, K.-W.; Won, Y.L.; Park, D.J.; Kim, Y.S.; Jin, E.S.; Lee, S.K. Combined toxic effects of polar and nonpolar chemicals on human hepatocytes (HepG2) cell by quantitative property-activity relationships modeling. Toxicol. Res. 2016, 32, 337-343. [CrossRef]

31. PubChem. Available online: https://pubchem.ncbi.nlm.nih.gov/ (accessed on 10 December 2019).

32. Balmer, M.E.; Buser, H.R.; Muller, M.D.; Poiger, T. Occurrence of the organic UV-filter compounds BP-3, 4-MBC, EHMC, and OC in wastewater, surface waters, and in fish from Swiss lakes. Environ. Sci. Technol. 2004, 39, 953-962. [CrossRef]

33. Kapler, R.; Crago, J.; Barr, J.; Arndt, J.; Setyowatu, K.; Chen, J. Toxicity biomarker expression in daphnids exposed to manufactured nanoparticles: Changes in toxicity with functionalization. Environ. Pollut. 2009, $157,1152-1156$.

34. Heinlaan, M.; Ivask, A.; Blinova, I.; Dubourguier, H.C.; Kahru, A. Toxicity of nanosized and bulk ZnO, CuO, and $\mathrm{TiO}_{2}$ to bacteria Vibrio fischeri and crustaceans Daphnia magna and Thamnocephalus platyrus. Chemosphere 2008, 71, 1308-1316. [CrossRef]

35. Fent, K.; Kunz, P.Y.; Zneker, A.; Rapp, M. A tentative environmental risk assessment of the UV-filters 3-(4-methylbenzylidene-camphor), 2-ethyl-hexyl-4-trimethoxycinnamate, benzophenone-3, benzophenone-4 and 3-benzylidene camphor. Mar. Environ. Res. 2010, 69, 54-56. [CrossRef]

36. Gago-Ferrero, P.; Díaz-Cruz, M.S.; Barceló, D. Occurrence of multiclass UV filters in treated sewage sludge from wastewater treatment plants. Chemosphere 2011, 84, 1158-1165. [CrossRef]

37. Mirabelle, M.P.T.; Leung, H.W.; Tak-Cheung, W.; Nobuyoshi, Y.; Sachi, T.; Wenhua, L.; Lam, P.K.S.; Murphy, M.B. Occurrence, distribution and ecological risk assessment of multiple classes of UV filters in surface water from different countries. Water Res. 2014, 67, 55-65.

(C) 2020 by the authors. Licensee MDPI, Basel, Switzerland. This article is an open access article distributed under the terms and conditions of the Creative Commons Attribution (CC BY) license (http://creativecommons.org/licenses/by/4.0/). 